\title{
Detection of iodine and bromine
}

\section{Alvaro Reynoso}

To cite this article: M. Alvaro Reynoso (1849) Detection of iodine and bromine, Philosophical Magazine Series 3, 35:234, 156-157

To link to this article: http://dx.doi.org/10.1080/14786444908646326

曲 Published online: 30 Apr 2009.

Submit your article to this journal $2 \pi$

Q View related articles $₫$ 
from this that the presence of certain fixed acids is favourable to the combination of alumina with oxide of cobalt. These observations explain the cause of failure which chemists occasionally incur, in attempting to prepare 'Thenard's blue without employing phosphate or arseniate of cobalt.-L'Institut, Juin 27, 1849.

\section{DETECTION OF IODINE AND BROMINE.} BY M. ALVARO REY NOSO.

The method employed to ascertain the presence of these bodies, when they exist as iodides or bromides, the author remarks, consists in dissolving them in water, to add starch in the state of paste, or ather and a few drops of solution of chlorine. The chlorine seizes the metal combined with the iodine or bromine, and these bodies colour the starch blue, or dissolve in the æther; but iodine and bromine having the property of combining directly with chlorine, and of forming a chloride of iodine or of bromine, the chlorine, in order to detect the presence of these bodies, ought not to be employed in excess; because the chlorides of iodine or bromine are decomposed by contact with water and produce hydrochloric acid, and iodic or bromic acid without acting on the starch or the æther.

This experiment was very difficult to perform; often, indeed, these bodies could not be discovered, and this was supposed to be owing to the above-described difficulty. Then the quantity of chlorine was diminished, from the fear of exceeding the requisite proportions, and it happened that the quantity of chlorine was not sufficient to set the iodine at liberty. The manner in which the chlorine was employed also increased this error ; in fact, it is well known that a solution of chlorine is weakened by keeping, and that eventually its power is lost, in spite of every possible precaution. Thus on pouring into a solution of an iodide or bromide a very small quantity of aqueous solution of chlorine, it happened that the iodine was not see free, and that all the chlorine was employed in forming hydrochloric acid. This method, then, was not applicable to the detection of small quantities of iodine or bromine, especially when these bodies are mixed with substances capable of seizing the chlorine. It was therefore desirable that the iodine or bromine should be isolated by means of a body incapable of acting upon them, whatever might be its excess. Oxygenated water fulfills these conditions ; it decomposes hydriodic or hydrobromic acid without at all acting upon the iodine or bromine set free by it.

The following is the method of proceeding for iodine : a bit of binoxide of barium is to be put into a small glass tube closed at one end; then are to be added to it distilled water, pure hydrochloric acid, and paste of starch; the operator is to wait till bubbles arise to the surface, and then the iodide is to be added. A rose-blue colour is immediately procured if the quantity of iodine is but small, but of a deep blue if the quantity of iodine is considerable.

It is more convenient to operate on these conditions; not only considering them as manipulations which become very easy, but also with regard to the success of the experiment. On this plan, the 
requisite excess of oxygenated water is certain to be employed when hyposulphites, sulphates, or sulphurets are present; besides, the hydrochloric acid employed in the preparation of the oxygenated water, acts an important part, for it serves to set hydriodic acid free,

$\mathrm{BaO}^{2}+(\mathrm{ClH})^{2}+\mathrm{IH}, \mathrm{KO}+\mathrm{HO}=\mathrm{BaO}, \mathrm{ClH}+\mathrm{KO}, \mathrm{ClH}+2(\mathrm{HO})+\mathrm{I}$.

Although it is unquestionable that the hydrochloric acid, by reacting on the binoxide of barium, in the presence of water, produces oxygenated water, the author was desirous of satisfying himself that it was in fact $\mathrm{HO}^{2}$ which actually produced the result obtained; for this purpose he substituted tartaric for hydrochloric acid, and obtained the same result. M. Thenard had also described the decomposition of hydriodic acid by pure oxygenated water.

When the iodides are mixed with chlorides, sulphurets, sulphites or hyposulphites, the process is equally correct; only, as by the action of hydrochloric acid on the sulphuret sulphuretted hydrogen is produced, which is decomposed by oxygenated water, and the hyposulphites and sulphites are converted into sulphate by absorbing oxygen, a larger quantity of oxygenated water is required than if the iodide was pure.

The hyposulphites and sulphites, on becoming sulphates, produce a precipitate of sulphate of barytes in the liquor; this might delay the action, if agitation were not employed to detach the sulphate of barytes from the surface of the binoxide of barium: it is also a precaution which ought always to be adopted to increase the production of oxygenated water. By this process the presence of iodine is readily detected in the urine of a patient taking 0.10 centigr. of iodide of mercury morning and evening. In the same urine no iodine could be detected by means of chlorine; this is therefore a case in which, notwithstanding every precaution, the iodine passed undetected by chlorine.

This process detects the presence of iodine in the ash of sponge. A drop of a solution of $0.010 \mathrm{grm}$. of iodide of potassium dissolved in a litre of water, produced, each time that it fell into the tube, a manifest blue colour at the surface. By agitation the blue colour disappeared, and the liquor assumed a rose tint; on adding another drop, a fresh blue colour is obtained at the surface. This process, therefore, very easily indicates less than $\frac{I}{100,000}$ of iodide of potassium. The process is the same for bromine, excepting that instead of starch ather is employed; agitation is used, the bromine dissolves in the æther, and it becomes of a more or less deep yellow colour according to the quantity.

When, however, iodides and bromides occur mixed, they are detected by adding an excess of starch and of ather. The iodine combines with the starch, and the bromine, dissolving in the æether, rises to the surface; so that the blue colour is obtained below, and the yellow tint high up.-Comptes Rendus, Avril 30, 1849. 